\title{
Reaction of Malondialdehyde with Deoxyribonucleosides in the Presence of Acetaldehyde
}

\author{
Takeshi OHYA \\ Faculty of Pharmaceutical Sciences, Josai University, 1-1, Keyakidai, Sakado, Saitama, 350-02, Japan. \\ Received April 22, 1994; accepted June 9, 1994
}

\begin{abstract}
The reactivity of malondialdehyde (MDA) with deoxyribonucleosides in the presence of acetaldehyde (AA) was investigated. Although MDA is known to be reactive towards deoxyguanosine (GdR), deoxyadenosine (AdR) and deoxycytidine (CdR) under acidic conditions, MDA had only slight reactivity towards GdR under physiological pH. However, when AA was present, MDA exhibited much higher reactivity towards GdR, and a reaction with AdR also took place.
\end{abstract}

Keywords malondialdehyde; nucleoside; acetaldehyde; deoxyguanosine; deoxyadenosine

Malondialdehyde (MDA) is produced as an end product of unsaturated lipid peroxidation ${ }^{1-4)}$ and as a side product of prostaglandin and thromboxane biosynthesis. ${ }^{5,6)}$

Since MDA is mutagenic, ${ }^{7,8)}$ the reactions of MDA with DNA $^{9-14)}$ and nucleosides have been investigated. It has been reported that MDA is reactive towards guanine, adenine and cytosine nucleosides under acidic conditions resulting in the formation of $1: 1$ and $1: 2 \mathrm{MDA}$-deoxyguanosine (GdR) adducts, ${ }^{15-17)} 1: 1$ and $1: 3 \mathrm{MDA}-$ adenosine adducts ${ }^{18-20)}$ and $1: 1$ and $1: 3$ MDA-deoxycytidine $(\mathrm{CdR})$ adducts. ${ }^{18,21)}$ However, the reaction of MDA with nucleosides under physiological $\mathrm{pH}$ has not been investigated.

On the other hand, acetaldehyde (AA) is produced along with MDA as an end product of unsaturated lipid peroxidation $^{3,22,23)}$ and by ethanol metabolism. In addition, it has been reported that the administration of ethanol increases the production of MDA. ${ }^{24)}$ The author ${ }^{25)}$ has previously shown that when an alkanal such as AA coexists, MDA is highly reactive with primary amines such as hexylamine under physiological conditions, forming a 1:1:1 adduct of MDA-alkanal-primary amine.

In the present study, the reactivity of MDA with GdR, deoxyadenosine (AdR), CdR and thymidine (TdR) in the presence of AA under physiological conditions was investigated.

\section{MATERIALS AND METHODS}

Apparatus High-performance liquid chromatography (HPLC) was performed using a Shimadzu LC-6A instrument equipped with a Shimadzu SPD-6A UV absorption detector.

Materials Sodium malondialdehyde (MDA $\cdot \mathrm{Na}$ ) was prepared as described in the literature. ${ }^{26)} \mathrm{AA}(99.5 \%)$ was purchased from Merck Co., Ltd. Deoxyribonucleosides were purchased from Wako Pure Chemical Industries.

Reaction of MDA with Deoxyribonucleoside in the Presence of AA A mixture of deoxyribonucleoside $(10 \mathrm{~mm}), \mathrm{MDA} \cdot \mathrm{Na}(20 \mathrm{~mm})$ and $\mathrm{AA}(20 \mathrm{mM})$ in $0.1 \mathrm{M}$ phosphate buffer $(\mathrm{pH} 7.4)$ was incubated at $37^{\circ} \mathrm{C}$ for $24 \mathrm{~h}$. The reaction mixture was diluted 10 -fold with water and $10 \mu \mathrm{l}$ of the solution was subjected to HPLC for determination of the remaining deoxyribonucleoside. HPLC analysis was performed on a $4.6 \times 250 \mathrm{~mm}$ octadecyl silica (ODS) column (Ultron $\mathrm{C}_{18}$, Shinwa Chemical Industries Co., Ltd.) with a mobile phase of $0.01 \mathrm{M}$ phosphate buffer ( $\mathrm{pH} 7.0)-\mathrm{MeOH}(80: 20, \mathrm{v} / \mathrm{v}$ ) (for the determination of remaining AdR), with a mobile phase of $\mathrm{H}_{2} \mathrm{O}-\mathrm{MeOH}-$ phosphoric acid $(90: 10: 0.1, \mathrm{v} / \mathrm{v} / \mathrm{v}$ ) (for the determinations of remaining $\mathrm{GdR}$ and $\mathrm{TdR}$ ) or with a mobile phase of $0.01 \mathrm{M}$ phosphate buffer ( $\mathrm{pH} 7.0)-\mathrm{MeOH}$ $(90: 10, v / v)$ (for the determination of remaining CdR) at a flow rate of $1 \mathrm{ml} / \mathrm{min}$. The absorbance was measured at $270 \mathrm{~nm}$ (for the determinations of remaining GdR, TdR and $\mathrm{CdR}$ ) or at $260 \mathrm{~nm}$ (for the determination of remaining AdR).

\section{RESULTS AND DISCUSSION}

Table I shows the loss of deoxyribonucleoside following reaction with MDA in the presence or absence of AA. A mixture of deoxyribonucleoside (10 mM), MDA (20 mM) and AA ( 0 or $20 \mathrm{~mm})$ in a phosphate buffer (pH 7.4) was incubated at $37^{\circ} \mathrm{C}$ for $24 \mathrm{~h}$, then the remaining deoxyribonucleoside was determined by HPLC. It has been reported that MDA was reactive towards GdR, AdR and $\mathrm{CdR}$ under acidic conditions. ${ }^{15-21)}$ However, under physiological $\mathrm{pH}$, MDA had a slight reactivity only towards GdR. On the other hand, when AA was present, MDA was found to exhibit much higher reactivity towards GdR and a reaction with AdR also took place.

TABLE I. Loss of Deoxyribonucleoside Caused by the Reaction with MDA in the Presence of AA

Loss of deoxyribonucleoside (\%)

GdR + MDA
AdR + MDA
CdR + MDA
TdR + MDA
GdR + MDA + AA
GdR + AA
AdR + MDA + AA
AdR + AA
CdR + MDA + AA
TdR + MDA + AA
3

0

0

0

29

0

13
0

0

$\mathrm{TdR}+\mathrm{MDA}+\mathrm{AA}$ 


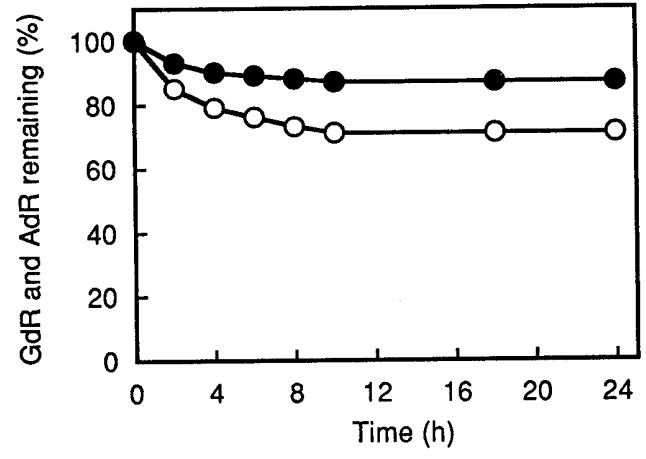

Fig. 1. Time Course of the Loss of GdR and AdR

A mixture of deoxyribonucleoside (10 mM), MDA (20 mM) and AA (20 mM) in $0.1 \mathrm{M}$ phosphate buffer ( $\mathrm{pH} 7.4$ ) was incubated at $37^{\circ} \mathrm{C} . \mathrm{O}, \mathrm{GdR} ; \boldsymbol{O}, \mathrm{AdR}$.

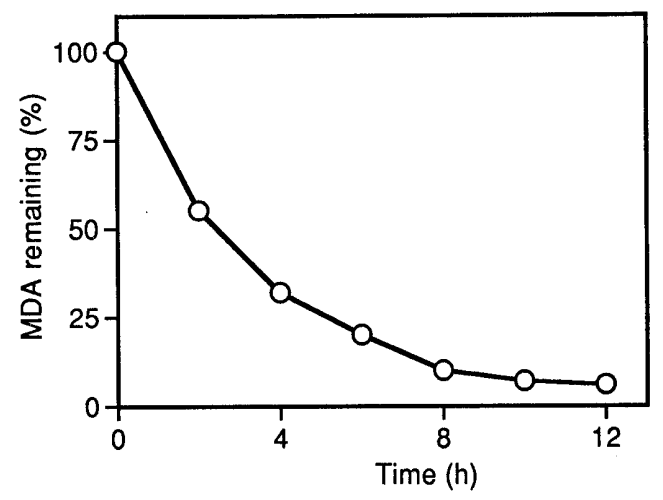

Fig. 2. Time Course of the Consumption of MDA by AA

A mixture of MDA (20 mM) and AA (20 mM) in $0.1 \mathrm{M}$ phosphate buffer (pH 7.4) was incubated at $37^{\circ} \mathrm{C}$. MDA remaining was determined by HPLC as described in the previous paper. ${ }^{27)}$
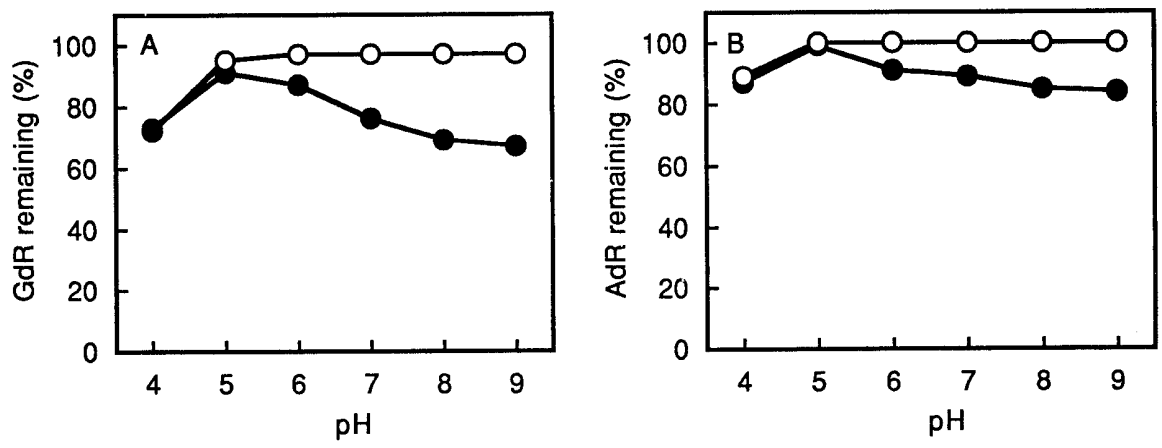

Fig. 3. Influence of $\mathrm{pH}$ on the Loss of $\operatorname{GdR}(\mathrm{A})$ and $\mathrm{AdR}(\mathrm{B})$

A mixture of deoxyribonucleoside $(10 \mathrm{mM})$ and MDA $(20 \mathrm{mM})(\mathrm{O})$ or a mixture of deoxyribonucleoside (10 mM), MDA (20 mM) and AA (20 mM) (O) in $0.1 \mathrm{M}$ citrate buffer (pH 4.0 and 5.0), 0.1 M phosphate buffer (pH 6.0-8.0) or $0.1 \mathrm{M}$ carbonate buffer (pH 9.0) was incubated at $37^{\circ} \mathrm{C}$ for $24 \mathrm{~h}$.

Figure 1 shows the time course of the loss of GdR and AdR during reaction with MDA in the presence of AA. The amounts of both GdR and AdR gradually decreased up to $10 \mathrm{~h}$. The author has shown in a previous paper ${ }^{27)}$ that AA is reactive towards MDA under physiological conditions. Figure 2 shows the time course of MDA consumption by AA at MDA and AA concentrations of $20 \mathrm{~mm}$. Hardly any MDA remained after $10 \mathrm{~h}$. Therefore, the decreases of GdR and AdR seemed to cease after $10 \mathrm{~h}$.

Figure 3 shows the influence of $\mathrm{pH}$ on the loss of GdR and AdR during the reaction with MDA in the presence or absence of AA. In the absence of AA, the loss of GdR and AdR took place under acidic conditions. In the presence of AA, the loss of GdR and AdR increased with increasing $\mathrm{pH}$, except in the case at $\mathrm{pH}$ 4.0. The loss of GdR and AdR at pH 4.0 may be due to a direct reaction of MDA with GdR and AdR.

Figure 4 shows the influence of AA concentration on the loss of GdR and AdR. The loss of GdR and AdR reached a maximum at an AA concentration of $20 \mathrm{~mm}$.

Since alkanals such as propanal and butanal are also produced along with MDA as the end products of unsaturated lipid peroxidation, ${ }^{4,28}$ the reaction of MDA with GdR or AdR in the presence of an alkanal was examined. A mixture of GdR or AdR (10 mM), MDA $(20 \mathrm{~mm})$ and alkanal $(20 \mathrm{~mm})$ in a phosphate buffer $(\mathrm{pH}$ 7.4) was incubated at $37^{\circ} \mathrm{C}$ for $24 \mathrm{~h}$. As shown in Table

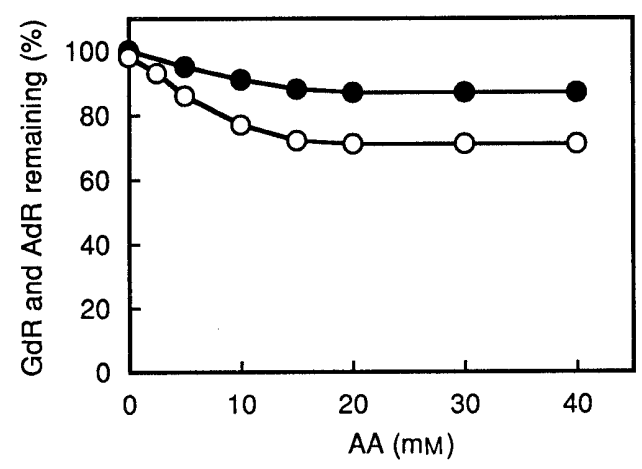

Fig. 4. Influence of AA Concentration on the Loss of GdR and AdR

A mixture of deoxyribonucleoside $(10 \mathrm{mM})$, MDA $(20 \mathrm{mM})$ and AA $(0-40 \mathrm{mM})$ in $0.1 \mathrm{M}$ phosphate buffer ( $\mathrm{pH} 7.4$ ) was incubated at $37^{\circ} \mathrm{C}$ for $24 \mathrm{~h}, \mathrm{O}, \mathrm{GdR}$; AdR.

II, in the presence of propanal or butanal, the reaction with GdR or AdR also took place.

From these results it was suggested that AA, which is produced by ethanol metabolism and during lipid peroxidation, can enhance the reactivity of MDA towards guanine and adenine nucleosides and probably towards DNA.

As described in the previous paper, ${ }^{25)}$ the reaction of MDA with a primary amine in the presence of AA produced a $1: 1: 1$ adduct of MDA-AA-primary amine and the yield of the adduct increased with increasing $\mathrm{pH}$. In 
TABLE II. Loss of GdR and AdR Caused by the Reaction with MDA in the Presence of Alkanal

\begin{tabular}{lc}
\hline \hline & Loss of GdR and AdR $(\%)$ \\
\hline GdR + MDA + AA & 29 \\
GdR + MDA + propanal & 26 \\
GdR + MDA + butanal & 26 \\
GdR + propanal & 0 \\
GdR + butanal & 0 \\
AdR + MDA + AA & 13 \\
AdR + MDA + propanal & 12 \\
AdR + MDA + butanal & 12 \\
AdR + propanal & 0 \\
AdR + butanal & 0 \\
\hline
\end{tabular}

addition, the author ${ }^{29)}$ has shown that MDA alone did not react with imidazole, but when AA was present a reaction took place and a 1:1:1 adduct of MDA-AAimidazole was produced. Similarly, the reactivity increased with increasing $\mathrm{pH}$. In the reaction of MDA with GdR or AdR in the presence of AA, the loss of GdR or AdR also increased with increasing $\mathrm{pH}$ as shown in Fig. 3. Therefore, it is suggested that the loss of GdR or AdR may be due to the formation of an MDA-AA-deoxyribonucleoside adduct. The structure of the reaction product is now being studied.

\section{REFERENCES}

1) H. Esterbauer, K. H. Cheeseman, Methods Enzymol., 186, 407 (1990).

2) D. R. Janero, Free Radical Biol. Med., 9, 515 (1990).

3) H. Tamura, K. Kitta, T. Shibamoto, J. Agric. Food Chem., 39, 439 (1991).

4) G. Poli, M. U. Dianzani, K. H. Cheeseman, T. F. Slater, J. Lang, H. Esterbauer, Biochem. J., 227, 629 (1985).
5) M. Hecker, M. Haurand, V. Ullrich, U. Diczfalusy, S. Hammarstrom, Arch. Biochem. Biophys., 254, 124 (1987).

6) U. Diczfalusy, P. Falardeau, S. Hammarstrom, FEBS Lett., 84, 271 (1977).

7) F. H. Mukai, B. D. Goldstein, Science, 191, 868 (1976).

8) A. K. Basu, L. J. Marnett, Carcinogenesis, 4, 331 (1983).

9) U. Reiss, A. L. Tappel, K. S. Chio, Biochem. Biophys. Res. Commun., 48, 921 (1972).

10) F. W. Summerfield, A. L. Tappel, Anal. Biochem., 111, 77 (1981).

11) F. W. Summerfield, A. L. Tappel, Anal. Biochem., 143, 265 (1984).

12) H. Seto, T. Seto, T. Takesue, T. Ikemura, Chem. Pharm. Bull., 34 5079 (1986).

13) C. E. Vaca, P. Vodicka, K. Hemminki, Carcinogenesis, 13, 593 (1992).

14) A. Kautiainen, C. E. Vaca, F. Granath, Carcinogenesis, 14, 705 (1993).

15) H. Seto, T. Okuda, T. Takesue, T. Ikemura, Bull. Chem. Soc. Jpn., 56, 1799 (1983)

16) L. J. Marnett, A. K. Basu, S. M. O'Hara, P. E. Weller, A. F. M. M. Rahman, J. P. Oliver, J. Am. Chem. Soc., 108, 1348 (1986)

17) A. K. Basu, S. M. O’Hara, P. Valladier, K. Stone, O. Mols, L. J. Marnett, Chem. Res. Toxicol., 1, 53 (1988).

18) V. Nair, G. A. Turner, R. J. Offerman, J. Am. Chem. Soc., 106, 3370 (1984).

19) H. Seto, T. Seto, K. Nagakura, H. Koike, Chem. Lett., 1993, 435.

20) K. Stone, M. Ksebati, L. J. Marnett, Chem. Res. Toxicol., 3, 33 (1990).

21) K. Stone, A. Uzieblo, L. J. Marnett, Chem. Res. Toxicol., 3, 467 (1990).

22) H. C. H. Yeo, T. Shibamoto, Lipids, 27, 50 (1992).

23) M. A. Shara, P. H. Dickson, D. Bagchi, S. J. Stohs, J. Chromatogr., 576, 221 (1992).

24) J. Moser, D. Bagchi, P. I. Akubue, S. J. Stohs, Alcohol \& Alcoholism, 28, 287 (1993).

25) T. Ohya, Biol. Pharm. Bull., 16, 137 (1993).

26) K. Kikugawa, Y. Ido, Lipids, 19, 600 (1984).

27) T. Ohya, Biol. Pharm. Bull., 16, 1078 (1993).

28) K. Yosino, M. Sano, M. Fujita, I. Tomita, Chem. Pharm. Bull., 39, 1788 (1991).

29) T. Ohya, Biol. Pharm. Bull., 17, 554 (1994). 